\title{
Conformational Transferability of the Sulfenyl Carbonyl Group -SC(O) - in Cyclic Thioesters
}

\author{
Nahir Y. Dugarte, ${ }^{\dagger}$ Mauricio F. Erben, ${ }^{* \dagger}{ }^{\dagger}$ Evamarie Hey-Hawkins, ${ }^{\ddagger}$ Peter Lönnecke, ${ }^{\ddagger}$ Sven Stadlbauer, ${ }^{\ddagger}$ \\ Mao-Fa Ge, ${ }^{\S}$ Yao Li, ${ }^{\S}$ Oscar E. Piro," Gustavo A. Echeverría," and Carlos O. Della Védova*,† \\ ${ }^{\dagger}$ CEQUINOR (UNLP-CONICET, CCT-La Plata), Departamento de Química, Facultad de Ciencias Exactas, Universidad Nacional \\ de La Plata, C.C. 962 (1900), La Plata, República Argentina \\ ${ }^{\ddagger}$ Institut für Anorganische Chemie der Universität Leipzig, Johannisallee 29, D-04103 Leipzig, Germany \\ ${ }^{\S}$ State Key Laboratory for Structural Chemistry of Unstable and Stable Species, Institute of Chemistry, Chinese Academy of Sciences, \\ Beijing 100080, China \\ "Departamento de Física, Facultad de Ciencias Exactas, Universidad Nacional de La Plata and Instituto IFLP (CONICET-UNLP, \\ CCT-La Plata), C.C. 67, 1900 La Plata, Argentina
}

Supporting Information

\begin{abstract}
The molecular and crystal structure of two dithiolactones (formally dimers of $\varepsilon$-caprothiolactone and $\omega$-hexadecathiolactone) have been determined by $\mathrm{X}$-ray diffraction at low temperature, revealing that the thioester group is planar with a synperiplanar orientation of the $\mathrm{C}=\mathrm{O}$ double bond with respect to the $\mathrm{S}-\mathrm{C}$ single bond. This conformational behavior is in contrast to that found for the smaller cyclic members of this family, where the antiperiplanar conformation is enforced. It is hypothesized that strain effects play a major role for the energy balance in the conformational preference. In this context, the molecular, vibrational (infrared and Raman), and electronic properties of $\varepsilon$-caprothiolactone have also been analyzed by using a combined experimental, including gas-phase helium I photoelectron spectroscopy, and computational approach.
\end{abstract}

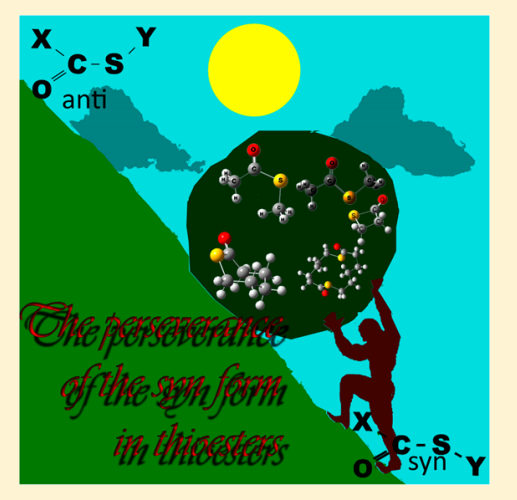

\section{INTRODUCTION}

The presence of a large lactone ring, usually a 14-16membered cycle, is an essential constituent of macrolides, which are widespread in antibiotics. Specific conformations are known for several of the macrolides, ${ }^{1}$ and their overall constitutional structures reveal an unusual wealth of stereochemical features involving asymmetric centers and conformational variations of the lactone rings. The general principles underlying the conformational behavior of lactones were understood after the work by Allinger ${ }^{2}$ and Thomas, ${ }^{3,4}$ who studied the small-ring representatives of this chemical family. Lactones are quite reactive and readily convert to their linear counterparts by polymerization reactions, which has been related to the release of ring strain. 5,6

Macrolides containing a thiolactone group are much less common species, even though the biochemical importance of protein-bound macrocyclic thiolactones was recognized early. ${ }^{7}$ In effect, small cyclic thiolactones are also very interesting molecules in biological terms, the most significant examples are the five-membered cycles homocysteine thiolactone $e^{8,9}$ and thiolactomycin, an antibiotic known for its remarkable selectivity and broad antibacterial spectrum. ${ }^{10}$ Thus, preparative methods are available in the chemical literature for the synthesis of thiolactone species. ${ }^{11-14}$ However, less is known about structural aspects of both small-sized and macrolide thio- lactones. Specifically, only the microwave spectrum of the nonsubstituted species was reported by Alonso et al., ${ }^{15}$ which allowed the determination of the moments of inertia and the nonplanarity of butyrothiolactone in the gas phase. Molecular and crystal structures of derivatives of higher molecular weight have also been studied by X-ray diffractometry. ${ }^{16,17}$ In this sense, a broader knowledge of the molecular structure of simple thiolactones is of major interest. Quite recently, the structural and electronic properties for the nonsubstituted four-, ${ }^{18}$ five--, ${ }^{19}$ and six-membered ${ }^{20}$ species have been studied in our group by using a combined experimental and quantum chemical approach. In all these molecules, the central $-\mathrm{SC}(\mathrm{O})$ - unit is forced to adopt an antiperiplanar (anti) conformation by the constraints of the ring system. It should be noted, however, that the preference of the synperiplanar (syn) conformation for noncyclic thioesters has been well recognized (Scheme 1).

The ubiquity of the $-\mathrm{SC}(\mathrm{O})$ - group in biochemistry suggests that thioesters have played an important role in the origin of life, especially as chemical reservoirs of energy in early metabolism. ${ }^{21,22}$ Recent work has shown that prebiotically relevant thioesters can survive hydrolysis in water for long

Received: May 7, 2013

Revised: June 5, 2013

Published: June 12, 2013 
Scheme 1. (A) Schematic Representation of the Conformational Equilibrium between the Syn and Anti Conformers for Thioester Compounds and (B) Constraints of the Ring Force Small Thiolactones To Adopt the Anti Form

A)<smiles>[X]C(=O)S[Y]C#CC</smiles>

syn

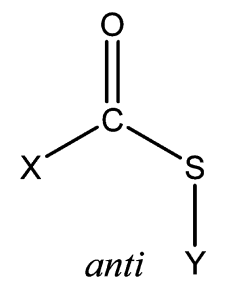

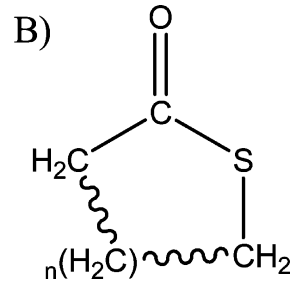

periods of time and conditions exist where the rate of thiolthioester exchange long exceeds the rate of hydrolysis. ${ }^{23}$

In this work, the seven-membered $\varepsilon$-caprothiolactone species $(n=7)$ is analyzed in terms of its structural, conformational and electronic properties, including the assignment of the gas-phase photoelectron spectrum. A systematic analysis of the structural, vibro-conformational, and electronic properties for the smallest members of the thiolactone family of compounds is presented, and the observed experimental trends are discussed on the basis of the computed strain energies. In an attempt to narrow the gap between simple thiolactone molecules and more complex macrolide species, two dithiolactone, formally dimers of $\varepsilon$ capro- and $\omega$-hexadecathiolactone, have been synthesized and their structural properties have been studied in relation with their monomeric counterparts.

\section{EXPERIMENTAL SECTION}

2.1. Synthesis. Bhar et al. ${ }^{12}$ reported a method for the synthesis of thiolactones by using the cyclization reaction of bromoalkanoyl chlorides with benzyltriethylammonium tetrathiomolybdate as a sulfur-transfer reagent. When 6-bromohexanoyl chloride is used, a mixture of $\varepsilon$-caprothiolactone monomer $(13 \%)$ and dimer $(16 \%)$ is obtained. The products were isolated and purified by flash column chromatography on silica gel using petroleum ether as eluent. The final purity in liquid and solid phase was carefully checked by reference to the IR (see Figures S1 and S2 (Supporting Information) and discussion below), GC-MS, and ${ }^{1} \mathrm{H}$ and ${ }^{13} \mathrm{C}$ NMR spectra. ${ }^{11,12}$ Single crystals of the $\varepsilon$-caprothiolactone dimer suitable for structural X-ray diffraction work were obtained after successive recrystallizations from a mixture of $\mathrm{THF} / n$-hexane at $-5{ }^{\circ} \mathrm{C}$.

Following a similar method, ${ }^{12}$ the novel dimer of $\omega$ hexadecathiolactone was prepared, using $3 \mathrm{mmol}$ of tetrathiomolybdate as a sulfur-transfer reagent together with $2 \mathrm{mmol}$ of 16-bromohexadecanoyl chloride in dry acetonitrile at room temperature. 16-Bromohexadecanoyl chloride was obtained by chlorination of 16-bromohexadecanoic acid [Br$\left(\mathrm{CH}_{2}\right)_{15} \mathrm{COOH}$, Sigma Aldrich, 99\%] with an excess of thionyl chloride using microwave radiation for $48 \mathrm{~h}$ at $100{ }^{\circ} \mathrm{C}$ and the product was characterized by IR spectroscopy [FT-IR/KBr $\left(\mathrm{cm}^{-1}\right)$ : 2925 (vs), 2854 (vs), 1800 (s), 1464 (s), 1403 (m), $1258(\mathrm{~m}), 1132(\mathrm{~m}), 953(\mathrm{~m}), 721(\mathrm{~m}), 680(\mathrm{~m}), 646(\mathrm{w}), 564$ $(\mathrm{m}), 432(\mathrm{~m})]$. After the usual workup, the crude product was obtained as a white solid and purified by column chromatography on silica gel using petroleum ether/EtOAc (95:5) as eluent. The product was further recrystallized from $\mathrm{CHCl}_{3} .{ }^{1} \mathrm{H}$ $\operatorname{NMR}\left(\mathrm{CDCl}_{3}\right)(\delta$ in ppm $): \delta=2.86(4 \mathrm{H} \mathrm{t}), \delta=2.52(4 \mathrm{H} \mathrm{t}), \delta$ $=1.40-1.80(8 \mathrm{H} \mathrm{m}), \delta=1.1-1.3(44 \mathrm{H} \mathrm{m})$. The melting point is $63.3(5){ }^{\circ} \mathrm{C}$, as determined by differential scanning calorimetry. The GC-MS analysis showed an intense peak at $m / z=270$ corresponding to the monomeric species [SCO$\left.\left(\mathrm{CH}_{2}\right)_{15}\right]^{+}$. Further information is obtained from the FT-IR spectrum shown in Figure S3 (Supporting Information), as discussed below.

2.2. Instrumentation. 2.2.1. IR and Raman Spectroscopy. IR absorption spectra in the liquid ( $\varepsilon$-caprothiolactone) and solid states (in $\mathrm{KBr}$ pellets for $\varepsilon$-caprothiolactone and $\omega$ hexadecathiolactone dimers) were recorded with a resolution of $2 \mathrm{~cm}^{-1}$ in the range $4000-400 \mathrm{~cm}^{-1}$ using a Bruker model EQUINOX 55 equipped with DLATGS detector with a $\mathrm{KBr}$ window. The FT-Raman spectra (liquid for $\varepsilon$-caprothiolactone and powdered solids for the $\varepsilon$-caprothiolactone and $\omega$ hexadecathiolactone dimers) were recorded in the region $4000-100 \mathrm{~cm}^{-1}$ using a Bruker IFS 66v spectrometer equipped with Nd:YAG laser source operating at $1064 \mathrm{~nm}$ line with 200 $\mathrm{mW}$ power of spectral width $2 \mathrm{~cm}^{-1}$.

2.2.2. Photoelectron Spectroscopy. The gas-phase PE spectrum of $\varepsilon$-caprothiolactone was recorded on a doublechamber UPS-II machine, which was designed specifically to detect transient species, as described elsewhere, ${ }^{24-26}$ at a resolution of about $30 \mathrm{meV}$, indicated by the standard $\operatorname{Ar}^{+}\left({ }^{2} \mathrm{P}_{3 / 2}\right)$ photoelectron band. Experimental vertical ionization energies were calibrated by simultaneous addition of a small amount of argon and methyl iodide to the sample.

2.2.3. Gas Chromatography-Mass Spectrometry. The GC-MS measurements were recorded with a GCMSQP2010 SHIMADZU instrument using gaseous helium as mobile phase with the pressure in the column head equal to $100 \mathrm{kPa}$. The column used was a 19091J-433 HP-5 of $30 \mathrm{~m} \times$ $0.32 \mathrm{~mm} \times 0.25 \mathrm{~mm}$ film thickness. Approximately $1 \mu \mathrm{L}$ volume of the compounds dissolved in $\mathrm{CHCl}_{3}$ was chromatographed under the following conditions: the injection temperature was $200{ }^{\circ} \mathrm{C}$, the initial column temperature $\left(70{ }^{\circ} \mathrm{C}\right)$ was held for $2 \mathrm{~min}$, then increased to $200^{\circ} \mathrm{C}$ at $10^{\circ} \mathrm{C} / \mathrm{min}$ and held for $4 \mathrm{~min}$, and finally increased to $250{ }^{\circ} \mathrm{C}$ at $10{ }^{\circ} \mathrm{C} / \mathrm{min}$ and held for $2 \mathrm{~min}$. In the spectrometer the source was kept at 200 ${ }^{\circ} \mathrm{C}$.

2.2.4. X-ray Diffraction Data. The measurements on the $\varepsilon$ caprothiolactone dimer were performed at low temperature $(T$ $=130 \mathrm{~K})$ on an Agilent Technologies Gemini diffractometer with graphite-monochromated $\mathrm{Mo} \mathrm{K} \alpha(\lambda=0.71073 \AA)$ radiation. The diffraction data of $\omega$-hexadecathiolactone dimer were collected at $T=100 \mathrm{~K}$ on an Oxford Xcalibur, Eos, Gemini CCD diffractometer with graphite-monochromated $\mathrm{Cu}$ $\mathrm{K} \alpha(\lambda=1.54184 \AA)$ radiation. $\mathrm{X}$-ray diffraction intensities were collected ( $\omega$ scans with $\vartheta$ - and $\kappa$-offsets), integrated and scaled with CrysAlisPro ${ }^{27}$ suite of programs. The unit cell parameters were obtained by least-squares refinement (based on the angular settings for all collected reflections with intensities larger than seven times the standard deviation of measurement errors) using CrysAlisPro. Data were corrected empirically for absorption employing the multiscan method implemented in CrysAlisPro. The structures were solved by direct methods with SHELXS $-97^{28}$ and the molecular models refined by full-matrix 


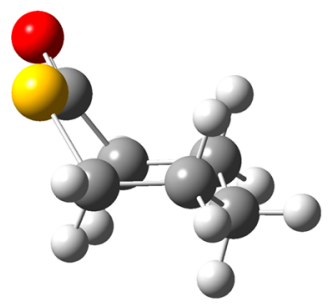

Chair (0.00)

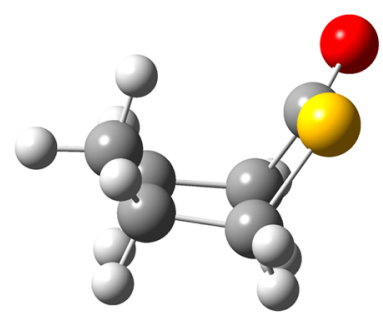

Boat (2.03)

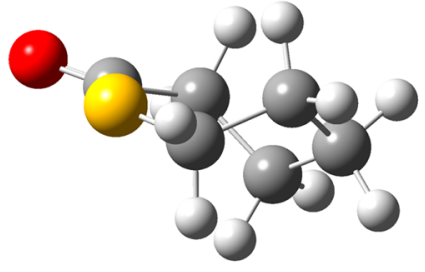

Twist-boat (3.34)

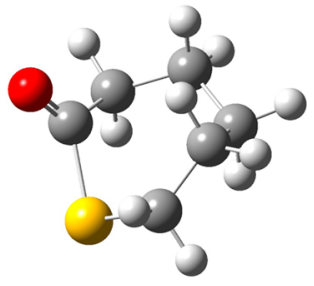

Envelope (9.58)

Figure 1. Molecular models computed for the three main conformations of $\varepsilon$-caprothiolactone with $\Delta E^{0}$ values given in parentheses (B3LYP/aug-ccpVTZ).
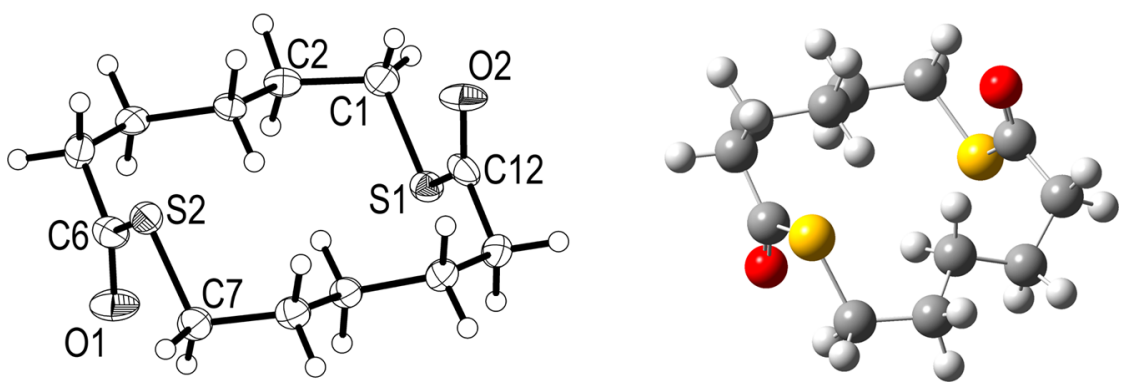

Figure 2. Left: view of one independent $\varepsilon$-caprothiolactone dimer in the solid state showing the labeling of the non- $\mathrm{H}$ atoms and their displacement ellipsoids at the $50 \%$ probability level. Right: corresponding molecular model from gas-phase calculations.

least-squares procedure on $F^{2}$ with SHELXL-97. ${ }^{29}$ Hydrogen atoms were positioned stereochemically and refined with the riding model. The asymmetric unit of $\varepsilon$-caprothiolactone accommodates three molecules with two of them located on crystallographic inversion centers. All these molecules are found to be completely disordered with a ratio of 0.591(3):0.409(3) (molecule at general position), and 0.570(4):0.430(4) and 0.724(4):0.276(4) for the center-symmetric molecules. Further details on crystal data and structure refinement are provided as Supporting Information (Tables S1 and S2). Full crystallographic data have been deposited with the Cambridge Crystallographic Data Centre (CCDC). Enquiries for data can be directed to: Cambridge Crystallographic Data Centre, 12 Union Road, Cambridge, U.K., CB2 1EZ or (e-mail) deposit@ccdc.cam.ac.uk or (fax) +44 (0) 1223 336033. Any request to the Cambridge Crystallographic Data Centre for this material should quote the full literature citation and the reference number CCDC 934413 ( $\varepsilon$-caprothiolactone dimer) and CCDC 934412 ( $\omega$-hexadecathiolactone dimer).

2.3. Quantum Chemistry. The calculations were performed using the GAUSSIAN $03^{30}$ program package. Full geometry optimizations were done by applying ab initio (MP2) and DFT (B3LYP) methods using the $6-311++\mathrm{G}(\mathrm{d}, \mathrm{p})$ and augcc-pVTZ basis set. The calculated vibrational properties corresponded in all cases to potential energy minima for which no imaginary frequency was found. The vertical ionization energies $\left(E_{\mathrm{v}}\right)$ were calculated according to Cederbaum's outer valence Green's function (OVGF) method $^{31,32}$ with the $6-311++G(d, p)$ basis set, based on the B3LYP/6-311++G(d,p) optimized geometry. The strain energy of $\varepsilon$-caprothiolactone has been calculated by applying the shomodesmotic approach introduced by Zhao and Gimarc. ${ }^{33}$ The formal reactions needed for computation of the ring strain are given as Supporting Information (Figure S4). To obtain the energies for all acyclic systems, optimum equilibrium geo- metries were computed for the singlet ground states of all pertinent molecular systems using B3LYP and MP2 methods with the $6-311++G(d, p)$ basis set. Several conformations were computed to ensure that the lowest energy conformation was obtained for each species. In all cases, electronic energies plus the zero-point energy were used to compute the strain energies.

\section{RESULTS AND DISCUSSION}

3.1. Conformational and Structural Analysis. 3.1.1. $\varepsilon^{-}$ Caprothiolactone. For the oxygen analogue, $\varepsilon$-caprolactone, rotational constants derived from microwave studies revealed that the most stable anti-chair conformation is the only conformation detectable in the gas phase. ${ }^{34}$ Recent high-level quantum chemical calculations (G3MP2 composite method) for $\varepsilon$-caprolactone result in five structures, the most stable one being the anti-chair conformation and suggesting that the second stable conformation corresponds to the boat conformation, higher in energy by $2.4 \mathrm{kcal} / \mathrm{mol}^{35}$

Following this approach, the conformational space of $\varepsilon$ caprothiolactone was first analyzed by using quantum chemical calculations. B3LYP method with large basis sets (aug-ccpVTZ) predicts that four structures are minimum energy conformations in the potential energy hypersurface, the computed molecular structures are shown in Figure 1. In all these forms an antiperiplanar orientation of the $\mathrm{C}=\mathrm{O}$ double bond and the $\mathrm{S}-\mathrm{C}$ single bond is observed, differences between them arising from the conformation adopted by the cycle. Thus, the most stable conformation corresponds to the chair conformation, followed by the boat conformation, which is less stable than the chair conformation by $2.0 \mathrm{kcal} / \mathrm{mol}$. The third conformation, which is $3.3 \mathrm{kcal} / \mathrm{mol}\left(\Delta E^{0}\right)$ less stable than the chair conformation, corresponds to the twist boat conformation. The inclusion of electron correlation at the MP2/aug-cc-pVTZ level of calculations (with ZPC energy at the B3LYP level using the same basis sets) diminishes the $\Delta E^{0}$ 


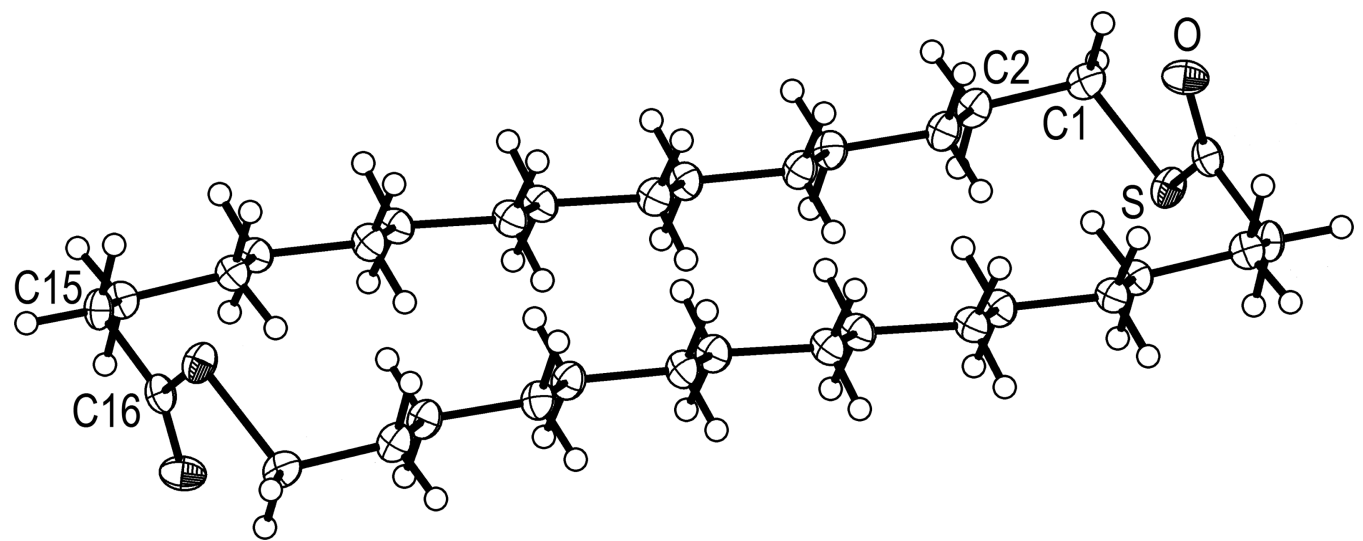

Figure 3. Molecular structure of $\omega$-hexadecathiolactone dimer in the solid state. The molecule is located on an inversion center. For simplicity, the labeling scheme is implicitly indicated by naming a few atoms at the beginning and end of a pleated $-\left(\mathrm{CH}_{2}\right)_{15}-$ strand.

energy difference between the chair and boat forms to 0.86 $\mathrm{kcal} / \mathrm{mol}$.

We carefully analyzed the vibrational data (see below), including the infrared and Raman spectra of liquid $\varepsilon$ caprothiolactone (see Figure S1 in the Supporting Information) assisted by frequency quantum chemical calculations for all forms. Very similar vibrational spectra are predicted for the different conformers. A small splitting is predicted for the ringbreathing vibrations, which are computed (B3LYP/aug-ccpVTZ) at 789, 799, and $804 \mathrm{~cm}^{-1}$ for the chair, boat and twist boat conformation, respectively. A single medium intensity absorption at $789 \mathrm{~cm}^{-1}$ is observed in the infrared spectrum of liquid $\varepsilon$-caprothiolactone, suggesting the presence of only one conformation in the liquid. However, the carbonyl stretching region shows the presence of quite broad bands centered at 1667 and $1664 \mathrm{~cm}^{-1}$ in the IR and Raman spectra, respectively. In the IR spectra, a shoulder is clearly defined at ca. $1676 \mathrm{~cm}^{-1}$, which could be indicative of a conformational equilibrium or of an association process. The computed values for the $\nu(\mathrm{C}=\mathrm{O})$ fundamentals are 1751 and $1760 \mathrm{~cm}^{-1}$ for the chair and boat conformations, respectively. Thus, it is plausible that both the boat and twist conformations coexist in equilibrium in liquid $\varepsilon$ caprothiolactone at room temperature.

3.1.2. $\varepsilon$-Caprothiolactone Dimer. There are three independent molecules present in the asymmetric unit, two of them are located on inversion centers. A DIAMOND ${ }^{36}$ plot of the third molecule (at a general position) is shown in Figure 2. The thiolactone groups $(-\mathrm{S}-\mathrm{C}=\mathrm{O}-)$ adopt a head-to-tail arrangement, with the carbonyl groups oriented in opposite directions, whereas the two $\mathrm{C}-\mathrm{S}-\mathrm{C}-\mathrm{C}$ moieties adopt a gauche conformation. Due to the size of the ring, with several accessible conformations within a range of a few $\mathrm{kcal} / \mathrm{mol}$, the sulfenyl carbonyl group conformation can adopt the preferred synperiplanar orientation. These features are in agreement with the structures of related polythiolactones, recently reported by Vujasinovic et al. ${ }^{37,38}$

3.1.3. $\omega$-Hexadecathiolactone Dimer. The cyclic thioester molecule (Figure 3) is located on a crystallographic inversion center. It adopts a ribbon-like conformation defined by two parallel and inversion-related pleated $-\left(\mathrm{CH}_{2}\right)_{15}-$ strands that are looped at their ends by linking sulfenyl carbonyl -SC(O)groups.

On the basis of the analysis performed for the simplest thiolactone species, we applied the B3LYP/6-311++G** for computing bond lengths and bond angles in the dimeric species, which compare fairly well with the values obtained from the X-ray analysis (see Tables S8 and S9 in the Supporting Information for the whole computed values). Some deviations are found for the bond lengths involving the sulfur atom. ${ }^{39}$ It is known, however, that in the comparison of crystal and gasphase structures, systematic differences due to intermolecular interactions (crystal-packing effects) in the solid phase have to be considered, especially for terminal bond lengths. ${ }^{40}$

A comparison of the molecular structures of the three thiolactone species studied here yields some interesting conclusions. Thus, it is clear that the conformational preference of the $-\mathrm{SC}(\mathrm{O})$ - group clearly depends on the size of the lactone ring. For $\varepsilon$-caprothiolactone, the $-\mathrm{SC}(\mathrm{O})-$ unit is forced to adopt an antiperiplanar conformation $[\delta(\mathrm{O}=\mathrm{C}-$ $\mathrm{SC})=180^{\circ}$, Figure 1] by the constraints of the ring system. When the ring size increases, e.g., by forming the dithiolactones as in the present case, the conformational preference is inverted and the synperiplanar conformation is adopted around the $\mathrm{C}-$ $\mathrm{S}$ bonds, with $\delta(\mathrm{O}=\mathrm{C}-\mathrm{SC})=0^{\circ}$. It is noteworthy that the syn arrangement is the preferred conformation experimentally observed in a vast number of noncyclic thioesters. ${ }^{41-43}$ Thus, it is plausible that in the seven-membered cyclic thiolactone, in which the $-\mathrm{SC}(\mathrm{O})$ - unit is forced to adopt an anti conformation, the strain energy would play a relevant role in the physicochemical properties. This point will be analyzed in the next sections.

3.2. Strain Energy. The trend in the molecular strain produced by decreasing the ring size in cyclic molecules is wellknown. ${ }^{44}$ On this basis, it would be expected that, when the size of the cycle is increased, the strain energy will decrease. The computed strain energy of $\varepsilon$-caprothiolactone is given in Table 1 and compared with the nearest smallest analogues $\beta$ -

Table 1. Comparison between the Strain Energy ( $\mathrm{kcal} / \mathrm{mol}$ ) of Thiolactones and Their Respective Lactone Species with Different Ring Sizes $(n=$ Number of Atoms Included in the Ring)

$\begin{array}{lcccc} & \begin{array}{c}\beta \text {-propio- } \\ (n=4)\end{array} & \begin{array}{c}\gamma \text {-butyro- } \\ (n=5)\end{array} & \begin{array}{c}\delta \text {-valero- } \\ (n=6)\end{array} & \begin{array}{c}\varepsilon \text {-capro- } \\ (n=7)\end{array} \\ \text { lactone } & 22.7^{a, 47} & 7.8^{a, 47} & 10.2^{a, 47} & 10.7^{d, 47} \\ \text { thiolactone } & 16.4^{b, 18} & 3.8^{b, 19} & 7.5^{c, 20} & 8.7^{c}\end{array}$

${ }^{a}$ Calculated at the CBS-Q level of approximation. ${ }^{b} \mathrm{G} 2 \mathrm{MP} 2$ values. ${ }^{c}$ This work, calculated at the MP2/6-311++G** level. ${ }^{d}$ Obtained with MM3. 
propiothiolactone, ${ }^{18} \gamma$-butyrothiolactone, ${ }^{19}$ and $\delta$-valerothiolactone. ${ }^{20}$ As has been recently reported by Ringer and Magers, ${ }^{45}$ homodesmic and hyperhomodesmic models result in similar strain energy values, whereas the isodesmotic reaction scheme yields strain values that are definitively underestimated. These authors also pointed out that the B3LYP method underestimates the strain energy. All these comments also apply to our calculations on the strain energy of $\varepsilon$-caprothiolactone.

The strain energy value for $\varepsilon$-caprothiolactone determined by using the hyperhomodesmic approach at the MP2/6-311+ $+\mathrm{G}(\mathrm{d}, \mathrm{p})$ level is $8.7 \mathrm{kcal} / \mathrm{mol}$. This value is slightly higher than that found for cycloheptane $(6.7 \mathrm{kcal} / \mathrm{mol}),{ }^{46}$ the "reference" molecule for a seven-membered cyclic species, and also for cycloheptanone $^{47}(3.74 \mathrm{kcal} / \mathrm{mol})$. However, the strain energy is lower than that of the oxygen analogue $\varepsilon$-caprolactone $(10.7$ $\mathrm{kcal} / \mathrm{mol}) .{ }^{47}$ This behavior agrees with the fact that the presence of a carbonyl group has little impact on the strain energy, but the replacement of a methylene group by an oxygen atom increases the strain of the ring lowering the conformational molecular flexibility. Thus, the tendency for the strain energy of seven-membered species related to the title compound is $\varepsilon$-caprolactone $>\varepsilon$-caprothiolactone $>$ cycloheptane > cycloheptanone.

To better understand the behavior of the lactone and thiolactone species, the ring strains of the cyclic oxo and thioester analogues are compared in Table 1. In Figure 4, the

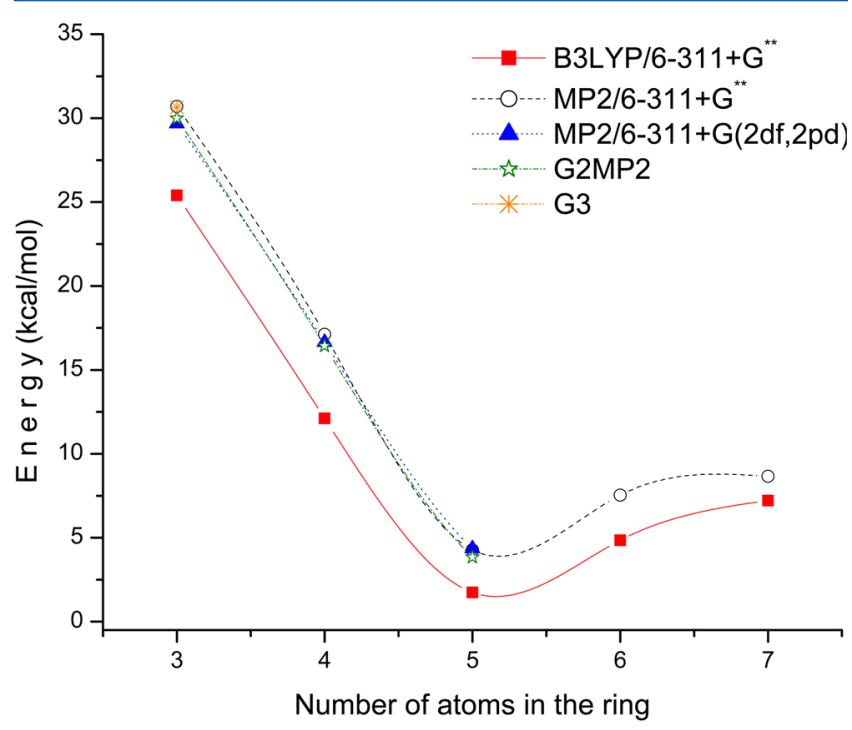

Figure 4. Graphical representation of the trend in the strain energy of the thiolactone species.

trend in the ring strain energy, calculated by the hyperhomodesmotic method for thiolactones mentioned in this work, $^{33}$ is represented graphically. The smallest hypothetical molecule "ethanethiolactone", a three-membered ring, has also been included in this series with a computed strain energy value of $30.6 \mathrm{kcal} / \mathrm{mol}$ at the high-level G3 methodology. The results also show the excellent agreement between the MP2 (with both sets of basis functions) and G2MP2 approximations.

A good correlation in the trend for both series is observed. The lowest strain energy for both lactone and thiolactone families corresponds to the five-membered ring species, the corresponding value for seven-membered rings being notably higher. Thus, in general, the increase of the number of atoms in the ring allows the carbonyl carbon and sulfur atom to adopt bond angle values closer to the geometry expected for the acyclic, ideally nonstrained species. However, the conformation requirement imposed by the ring also affects the neighboring methylene groups. For better comparison, experimental and calculated [B3LYP/6-311++G(d,p)] bond angles for thiolactone species are given in Table 2 . It is observed that the bond angles around both methylene groups directly bonded to the $-\mathrm{SC}(\mathrm{O})$ - moiety adopt values closer to that expected for an $\mathrm{sp}^{3}$ carbon atom $\left(109.5^{\circ}\right)$ when a five-membered ring is formed. These angles are notably lower for the highly strained four-membered species, amounting to $95.68(9)^{\circ}$ for the bond angle around the $\mathrm{C}_{\alpha}$ atom of propiothiolactone. ${ }^{18}$ On the other hand, the values are higher than $109.5^{\circ}$ for the six-membered and seven-membered molecules, i.e., $117.26(7)^{\circ}$ for the $\angle \mathrm{C}(\mathrm{O})-\mathrm{C}_{\alpha}-\mathrm{C}_{\beta}$ of $\delta$-valerothiolactone ${ }^{19}$ and $114.6^{\circ}$ (B3LYP/ $\left.6-311++\mathrm{G}^{* *}\right)$ for the same angle of $\varepsilon$-caprothiolactone. A similar trend is observed in the oxygen analogues, with $\angle \mathrm{C}(\mathrm{O})-\mathrm{C}_{\alpha}-\mathrm{C}_{\beta}$ values of $115.7^{\circ}$ and $113.9^{\circ}$ (B3LYP/6-311+ $\left.+\mathrm{G}^{* *}\right)$ for $\delta$-valerolactone and $\varepsilon$-caprolactone, respectively.

3.3. Vibrational Analysis. In lactones, the effect of the strain distortion in the molecular structure was observed in the vibrational spectra (infrared and Raman) by Saiyasombat and co-workers. ${ }^{48}$ The normal modes related with the lactone group are sensitive toward the strain energy and an increment in the frequency values of the $\nu\left(\mathrm{CH}_{2}-\mathrm{O}\right)$ and $\nu(\mathrm{O}-\mathrm{C}=\mathrm{O})$ stretching modes is noted when the ring size increases. To elucidate whether a similar effect is valid for thiolactones, the infrared and Raman spectra of $\varepsilon$-caprothiolactone have been measured in the liquid phase (Figure S1, Supporting Information) and the results obtained from the theoretical calculations were used to assign these vibrational spectra. For $\varepsilon$ caprothiolactone, the most intense band in the IR spectrum at $1667 \mathrm{~cm}^{-1}$ corresponds to $\nu(\mathrm{C}=\mathrm{O})$ and the signal at $595 \mathrm{~cm}^{-1}$ (597 $\mathrm{cm}^{-1}$ in Raman) can be assigned with confidence to the $\nu(\mathrm{S}-\mathrm{C})=\mathrm{O}$ stretching mode. The $\nu\left(\mathrm{S}-\mathrm{CH}_{2}\right)$ stretching mode is observed in the infrared spectrum at $663 \mathrm{~cm}^{-1}$ as a low intensity signal and in the Raman spectrum at $664 \mathrm{~cm}^{-1}$ as a medium intensity signal. These last observations are in agreement with the quantum chemical calculations, which compute a very low absorption at $648 \mathrm{~cm}^{-1}$ (B3LYP/6-311+ $\left.+\mathrm{G}^{* *}\right)$ for this mode. The opposite trend is true for open chair thioesters, where the $\mathrm{C}\left(\mathrm{sp}^{2}\right)-\mathrm{S}$ wavenumber appears at higher energies than the $\mathrm{C}\left(\mathrm{sp}^{3}\right)-\mathrm{S}$ value. ${ }^{49}$ Vibrational data for the $\beta$ propio-, ${ }^{18,50} \gamma$-butyro, ${ }^{19}$ and $\delta$-valerothiolactones ${ }^{20}$ have already been reported. Relevant vibrational data for these thiolactone species are collected in Table 3. Contrary to the behavior observed in lactones, ${ }^{48}$ the frequency values for the $\nu\left(\mathrm{CH}_{2}-\mathrm{S}\right)$ and $\nu(\mathrm{S}-\mathrm{C}(\mathrm{O}))$ normal modes slightly decrease when the size of the thiolactone ring increases from $\beta$-propio- to $\varepsilon$-caprothiolactone. This difference could be attributed to the fact that ring strain energies (and the geometry distortions) are much higher for the oxygen analog and thus, the influence exerted by the ring strain is a dominant factor. For thiolactones, other factors that also depend on the size of the alkylene chain [for instance the inductive effect exerted by the $-\left(\mathrm{CH}_{2}\right)_{n}$ - group] seem to influence the force constants of the $-\mathrm{SC}(\mathrm{O})-$ moiety.

These trends observed for the monomeric species are also valid for the dimeric species studied here. The solid-phase FTIR (in $\mathrm{KBr}$ pellets) and Raman spectra of the $\varepsilon$ caprothiolactone and $\omega$-hexadecathiolactone dimers are shown in Figures S2 and S3 (Supporting Information), respectively. The relevant IR absorptions and Raman dispersion frequencies are compared in Table 3 with the corresponding 
Table 2. Comparison of Geometrical Parameters of the Thiolactone Group

\begin{tabular}{|c|c|c|c|c|}
\hline $\mathcal{L} \varepsilon$ & & Bond Angle & & \\
\hline & $\mathrm{C}-\mathrm{S}-(\mathrm{C}=\mathbf{O})$ & $\mathbf{S}(\mathbf{C}=\mathbf{O}) \mathbf{C}_{\boldsymbol{\alpha}}$ & $(C=O) C_{\alpha}-C_{\beta}$ & $\mathbf{C S}-\mathbf{C}=\mathbf{O}\left({ }^{\circ}\right)$ \\
\hline$\beta$-propiothiolactone ${ }^{a}(\mathrm{n}=4)$ & $77.27(5)$ & $94.55(7)$ & $95.68(9)$ & 178.1(1) \\
\hline$\gamma$-butyrothiolactone ${ }^{b}(\mathrm{n}=5)$ & 93.1 & 110.0 & 108.3 & 178.5 \\
\hline$\delta$-valerothiolactone ${ }^{a}(\mathrm{n}=6)$ & $106.80(8)$ & $121.19(6)$ & $117.26(7)$ & $176.26(8)$ \\
\hline E-caprothiolactone ${ }^{b}(n=7)$ & 106.7 & 119.9 & 114.6 & 178.4 \\
\hline E-caprothiolactone $\operatorname{dimer}^{c}(n=14)$ & 101.0(7) & $122.2(4)$ & $114.0(7)$ & $5(1)$ \\
\hline$\omega$-hexadecathiolactone dimer $^{c}(n=34)$ & 101.72(10) & $112.72(15)$ & $111.81(17)$ & $5.4(2)$ \\
\hline
\end{tabular}

${ }^{a}$ Experimental data from X-ray molecular structure for $\beta$-propiothiolactone (mean values for crystallographic nonequivalent molecules) ${ }^{18}$ and $\delta$ valerothiolactone. ${ }^{19}{ }^{b}$ Values computed at the B3LYP/6-311++G** level of approximation. ${ }^{20}{ }^{c}$ This work.

Table 3. Selected Vibrational Data $\left(\mathrm{cm}^{-1}\right)$ for Thiolactone Species

\begin{tabular}{|c|c|c|c|c|c|c|c|c|c|}
\hline \multirow[b]{2}{*}{ species } & \multicolumn{3}{|c|}{$\nu \mathrm{C}=\mathrm{O}$} & \multicolumn{3}{|c|}{$\nu\left(\mathrm{S}-\mathrm{CH}_{2}\right)$} & \multicolumn{3}{|c|}{$\nu(\mathrm{S}-\mathrm{C}=\mathrm{O})$} \\
\hline & IR & $\operatorname{Raman}^{b}$ & $\mathrm{calc}^{a}$ & IR & $\operatorname{Raman}^{b}$ & $\mathrm{calc}^{a}$ & IR & $\operatorname{Raman}^{b}$ & $\mathrm{calc}^{a}$ \\
\hline$\beta$-propiothiolactone $(n=4)^{18,50}$ & $1759^{b}$ & $1763^{b}$ & 1855 & $744^{a}$ & $739^{b}$ & 738 & $653^{a}$ & $662^{b}$ & 652 \\
\hline$\gamma$-butyrothiolactone $(n=5)^{19}$ & $1704^{b}$ & $1702^{b}$ & 1793 & 685 & $687^{b}$ & 681 & $628^{b}$ & $632^{b}$ & 617 \\
\hline$\delta$-valerothiolactone $(n=6)^{20}$ & $1663^{b}$ & $1663^{b}$ & 1754 & 670 & $651^{b}$ & 654 & $601^{b}$ & $591^{b}$ & 580 \\
\hline$\varepsilon$-caprothiolactone $(n=7)^{d}$ & $1667^{b}$ & $1664^{b}$ & 1751 & 640 & $664^{b}$ & 648 & $595^{b}$ & $597^{b}$ & 586 \\
\hline$\varepsilon$-caprothiolactone dimer $(n=14)^{d}$ & $1686^{c}$ & $1682^{c}$ & 1757 & $670^{c}$ & $668^{c}$ & 655 & $579^{c}$ & $575^{c}$ & 485 \\
\hline$\omega$-hexadecathiolactone dimer $(n=34)^{d}$ & $1690^{c}$ & $1690^{c}$ & & $697^{c}$ & $669^{c}$ & & $601^{c}$ & & \\
\hline
\end{tabular}

${ }^{a} \mathrm{~B} 3 \mathrm{LYP} / 6-311++\mathrm{G}^{* *}$ level of approximation. ${ }^{b}$ Liquid. ${ }^{c}$ Solid (as KBr pellets for IR). ${ }^{d}$ This work.

calculated values. It is noteworthy that the most intense IR band corresponds to the $\mathrm{C}=\mathrm{O}$ vibration, at 1686 and 1690 $\mathrm{cm}^{-1}$ for $\varepsilon$-caprothiolactone and $\omega$-hexadecathiolactone dimers, respectively. Both dimers show a blue shift $\left(+19\right.$ and $+20 \mathrm{~cm}^{-1}$, respectively $)^{11}$ compared to the corresponding monomers. The $\nu(\mathrm{S}-\mathrm{C})=\mathrm{O}$ absorptions appear at 579 and $601 \mathrm{~cm}^{-1}$, in good agreement with the observed values for the monomeric thiolactone.

3.4. Helium I Photoelectron Spectra. The gas-phase PE spectrum of $\varepsilon$-caprothiolactone is presented in Figure 5. The experimentally observed ionization energies (IP, eV), calculated vertical ionization energies at OVGF/6-311++G $(\mathrm{d}, \mathrm{p})\left(E_{\mathrm{v}}, \mathrm{eV}\right)$, molecular orbitals, and assignment are summarized in Table 4.

Two bands appear overlapped at 9.29 and $9.44 \mathrm{eV}$; their narrow and sharp contours are characteristic of ionization from essentially nonbonding orbitals, which suggests these bands are associated primarily with the ionization of sulfur and oxygen lone-pair electrons $\left(\mathrm{n}_{\mathrm{S}}, \mathrm{n}_{\mathrm{O}}\right)$ of the $-\mathrm{SC}(\mathrm{O})-$ group, respectively. This assignment is in agreement with the results of $a b$ initio calculations, with respect to the ordering of the orbitals, as shown in Table 4. The same orbital ordering has been reported for the four-, five-, and six-membered thiolactone species $^{18-20}$ and also for related acyclic molecules, for example, thioacetic acid, ${ }^{24}$ S-alkyl thioacetates, ${ }^{51}$ and $\mathrm{XC}(\mathrm{O}) \mathrm{SCl}(\mathrm{X}=$ $\mathrm{F}^{52}$ and $\mathrm{Cl}^{24}$ ) species. For the first band $\left(\mathrm{n}_{\mathrm{S}}\right)$, the value observed for the vertical ionization $(9.29 \mathrm{eV})$ is in reasonable agreement with the theoretically predicted value of $8.96 \mathrm{eV}$ [ROVGF/6-311++G(d,p)].

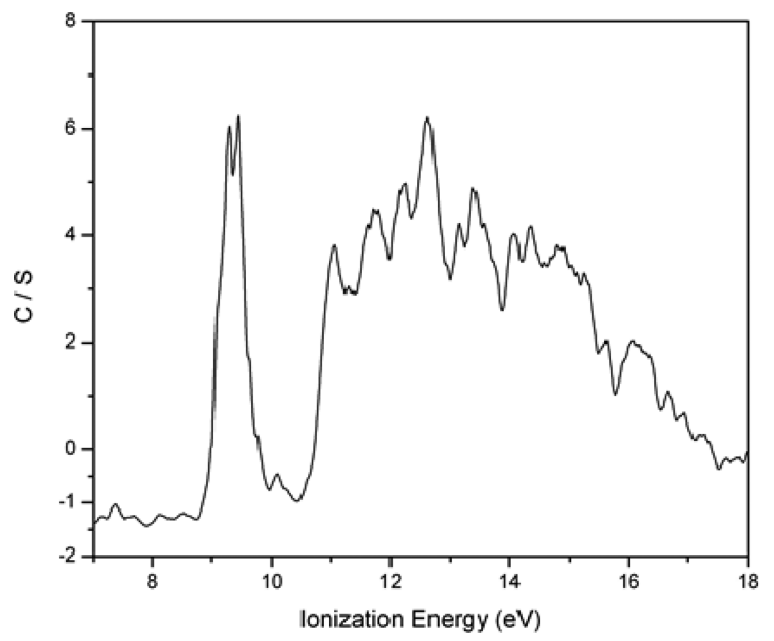

Figure 5. Photoeletron spectrum of $\varepsilon$-caprothiolactone.

There is a relatively large gap between the second and the third band, the latter having an ionization energy of $11.07 \mathrm{eV}$. The calculations predict that this band is associated with an ionization of electrons mainly localized in the $\pi_{\mathrm{C}=\mathrm{O}}$ orbital. A group of overlapping bands appears between 12 and $16 \mathrm{eV}$, which can be assigned to ionizations from several $\sigma-\mathrm{CH}_{2}$ orbitals, as predicted by the calculations.

The schematic representation of the three HOMOs (highest occupied molecular orbitals) of $\varepsilon$-caprothiolactone is given in Figure 6. The first three IPs of the molecule are correlated with 
Table 4. Experimental Vertical Ionization Energies (IP, eV), Computed Ionization Energies $\left(E_{\mathrm{v}}, \mathrm{eV}\right)$ at the OVGF/6$311++G(d, p)$ Level of Approximation and Assignment for $\varepsilon$ Caprothiolactone

$\begin{array}{rrll}\text { IP }(\mathrm{eV}) & E_{\mathrm{v}}(\mathrm{eV})^{a} & \mathrm{MO} & \text { assignment } \\ 9.29 & 8.96 & (35) & \mathrm{n}_{\mathrm{S}} \\ 9.44 & 9.55 & (34) & \mathrm{n}_{\mathrm{O}} \\ 11.07 & 11.86 & (33) & \pi_{\mathrm{C}=\mathrm{O}} \\ 11.73 & 12.13 & (32.31) & \sigma_{\mathrm{C} 4-\mathrm{Hs}} \\ 12.23 & 12.31 & & \\ 12.63 & 12.44 & (30.29) & \sigma_{\mathrm{C} 3-\mathrm{Hs}} \\ 13.15 & 12.84 & & \\ 13.40 & 13.48 & (28.27) & \sigma_{\mathrm{C} 5-\mathrm{Hs}} \\ 14.07 & 13.74 & & \\ 14.35 & 14.30 & (26.25) & \sigma_{\mathrm{C} 2-\mathrm{Hs}} \\ 14.86 & 14.89 & & \end{array}$

${ }^{a}$ Molecular geometry calculated at the B3LYP/6-311++G(d,p) level of approximation.

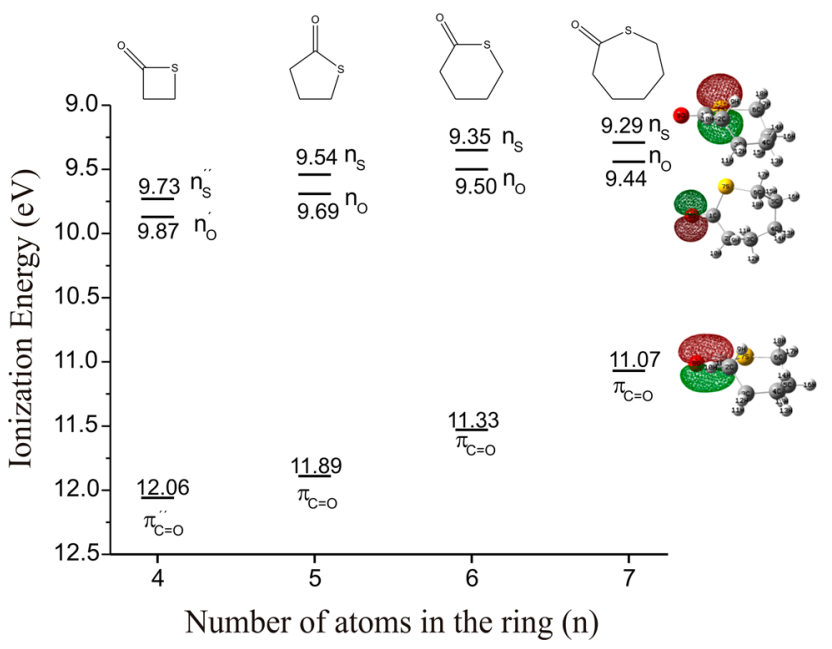

Figure 6. Depiction of three HOMOs (highest occupied molecular orbitals) of $\varepsilon$-caprothiolactone and correlation diagram of the ionization potentials of $\beta$-propiothiolactone, $\gamma$-butyrothiolactone, $\delta$ valerothiolactone, and $\varepsilon$-caprothiolactone.

the corresponding values determined for $\beta$-propiothiolactone, ${ }^{18}$ $\gamma$-butyrothiolactone, ${ }^{19}$ and $\delta$-valerothiolactone ${ }^{20}$ in the diagram shown also in this figure. The prominent feature is the diminution of the ionization energy of the three outermost orbitals when the ring size increases. Resonance or mesomeric effects in the $-\mathrm{C}(\mathrm{O}) \mathrm{S}$ - group promote a local planar geometry and are dominated by the donor-acceptor interaction from the out-of-plane lone pair $\mathrm{n}^{\prime \prime}{ }_{\mathrm{S}}$ orbital with the vacant $\pi^{*}{ }_{\mathrm{C}=\mathrm{O}}$. The nonplanarity of the five-, six- and seven-membered thiolactone rings would prevent this interaction. Thus, to consider the most important intramolecular interactions present in these species, the donor-acceptor interaction energies for $\beta$-propio-, $\gamma$ butyro-, $\delta$-valero-, and $\varepsilon$-caprothiolactone species have been evaluated by using the NBO population analysis. ${ }^{53,54}$ At the B3LYP/6-311++G(d,p) level, the contribution of the $\mathrm{n}^{\prime \prime} \rightarrow$ $\pi^{*}{ }_{\mathrm{C}=\mathrm{O}}$ interaction is $27.9,28.8,26.3$, and $29.0 \mathrm{kcal} / \mathrm{mol}$ for these thiolactone species, respectively. These results suggest that the electronic interaction is not much affected by the low nonplanarity of the thiolactone ring. The local planar symmetry around the carbonyl $\mathrm{sp}^{2}$ carbon atom leads to an efficient electronic conjugation. These results are in agreement with the early suggestion of Chin et al. that the electronic properties of thiolactones are determined primarily by inductive electronic donations from the alkyl chain. ${ }^{55} \mathrm{~A}$ similar behavior was reported by Isaksson and Lijefors for five-, six-, and sevenmembered cyclic oxamides. ${ }^{56}$

\section{CONCLUSION}

The molecular structure of thiolactones is strongly influenced by the size of the ring. Small-sized species are forced to adopt an antiperiplanar conformation of the $\mathrm{C}=\mathrm{O}$ double bond and $\mathrm{S}-\mathrm{C}_{\alpha}$ single bond. As shown in this work, the conformational landscape of the medium-sized $\varepsilon$-caprothiolactone $(n=7)$ is still dominated by an anti conformation around the $-\mathrm{SC}(\mathrm{O})-$ group. In contrast, the synperiplanar conformation is preferred for larger cycles such as the dimers of $\varepsilon$-caprothiolactone $(n=$ $14)$ and $\omega$-hexadecathiolactone $(n=34)$. The size of the ring also energetically favors the number of conformations accessible to adopt a syn arrangement around the $-\mathrm{SC}(\mathrm{O})-$ group. The syn form is the most stable conformer found for acyclic thioester analogues. Thus, strain effects seem to determine the conformational properties. The effects of the alkyl chain both in the computed strain energy and in the valence electronic levels have been clarified. Following the usually accepted trend, the increase of the number of atoms in the ring allows the carbonyl carbon and sulfur atom to adopt bond angle values which are closer to the geometry expected for the acyclic, ideally nonstrained species. However, the conformation requirement imposed by the ring also affects the neighboring methylene groups. The lowest strain energy value was determined for $\gamma$-butyrothiolactone $(n=5)$. The alkyl chain also determines the valence electronic properties through inductive effect.

\section{ASSOCIATED CONTENT}

\section{Supporting Information}

Crystallographic details and data, lists of atomic coordinates, equivalent isotropic displacement coefficients and anisotropic displacement parameters are given in Tables S1-S7. Tables S8 and S9 list selected experimental and computed (B3LYP/6$\left.311++\mathrm{G}^{* *}\right)$ geometrical parameters for the dimeric compounds. The FT-IR and FT-Raman spectra of the three compounds studied here are shown in Figures S1-S3. The formal reactions used for the ring strain of $\varepsilon$-caprothiolactone are shown in Figure S4. This material is available free of charge via the Internet at http://pubs.acs.org.

\section{AUTHOR INFORMATION}

\section{Corresponding Author}

*Tel/Fax:+54-221-425-9485. E-mail: (M.F.E.) erben@quimica. unlp.edu.ar, (C.O.D.V.) carlosdv@quimica.unlp.edu.ar.

Notes

The authors declare no competing financial interest.

\section{ACKNOWLEDGMENTS}

We thank CONICET (PIP 1529), ANPCYT (PME06 2804 and PICT06 2315), CICBA, and UNLP of Argentina for financial support. M.F.E., O.E.P., G.A.E., and C.O.D.V. are research fellows of CONICET.

\section{REFERENCES}

(1) Fajdetić, A.; Vinter, A.; Paljetak, H. Č.; Padovan, J.; Jakopović, I. P.; Kapić, S.; Alihodžić, S.; Filić, D.; Modrić, M.; Košutić, Hulita. 
Synthesis, Activity and Pharmacokinetics of Novel Antibacterial 15Membered Ring Macrolones. Eur. J. Med. Chem. 2011, 46, 3388-3397.

(2) Allinger, N. L. On the Conformations of Lactone Rings. Pure Appl. Chem. 1982, 54, 2515-2522.

(3) Thomas, S. A. Conformations of Saturated and Unsaturated $\delta$ Lactone Rings. J. Chem. Crystallogr. 1985, 15, 115-131.

(4) Thomas, S. A.; Agbaji, E. B. Molecular Conformations of $\gamma$ Lactone Rings from Crystal Structure Data. J. Chem. Crystallogr. 1989, 19, 3-23.

(5) Coulembier, O.; Degée, P.; Hedrick, J. L.; Dubois, P. From Controlled Ring-Opening Polymerization to Biodegradable Aliphatic Polyester: Especially Poly(b-malic acid) Derivatives. Prog. Polym. Sci. 2006, 31, 723-747.

(6) Alemán, C.; Betran, O.; Casanovas, J.; Houk, K. N.; Hall, H. K. Thermodynamic Control of the Polymerizability of Five-, Six-, and Seven-Membered Lactones. J. Org. Chem. 2009, 74, 6237-6244.

(7) Khan, S. A.; Erickson, B. W. Synthesis and Regioselective Hydrolysis of Peptides Containing an Internal Residue of Pyroglutamic Acid. J. Am. Chem. Soc. 1984, 106, 798-799.

(8) Jakubowski, H. Protein Homocysteinylation: Possible Mechanism Underlying Pathological Consequences of Elevated Homocysteine Levels. FASEB J. 1999, 13, 2277-2283.

(9) Jakubowski, H. Homocysteine Thiolactone: Metabolic Origin and Protein Homocysteinylation in Humans. J. Nutr. 2000, 130, 377S381 .

(10) Oishi, H.; Noto, T.; Sasaki, H.; Suzuki, K.; Hayashi, T.; Okazaki, H.; Ando, K.; Sawada, M. Thiolactomycin, a New Antibiotic. I. Taxonomy of the Producing Organism, Fermentation and Biological Properties. J. Antibiot. (Tokyo) 1982, 35, 391-395.

(11) Steliou, K.; Salama, P.; Corriveau, J. Reagents for Organic Synthesis. 4. Group 14 Metal Assisted Carbon-Sulfur Bond Formation. J. Org. Chem. 1985, 50, 4969-4971.

(12) Bhar, D.; Chandrasekaran, S. Synthesis of Thiolactones using Benzyltriethylammonium Tetrathiomolybate as Sulfur Transfer Reagent. Tetrahedron 1997, 53, 11835-11842.

(13) Dalla Cort, A.; Ercolani, G.; Iamiceli, A. L.; Mandolini, L.; Mencarelli, P. Macrocyclization under Kinetic Control. A Theoretical Study and Its Application to the Synthesis of Macrocyclic Poly(thiolactones). J. Am. Chem. Soc. 1994, 116, 7081-7087.

(14) Dalla Cort, A.; Mandolini, L.; Roelens, S. An Improved Procedure for the Synthesis of Macrocyclic Poly(thialactones). The Dramatic Effect of Reactant Mixing. J. Org. Chem. 1992, 57, 766-768.

(15) Alonso, J. L. The Non-planarity of the Ring Atoms in 2Oxotetrahydrothiophen. J. Chem. Soc., Chem. Commun. 1981, 12, 577578.

(16) Nawata, Y.; Sasaki, H.; Oishi, H.; Suzuki, K.; Sawada, M.; Ando, K.; Iitaka, Y. Structure of Thiolactomycin. Acta Crystallogr. 1989, C45, 978-979.

(17) Freer, S. T.; Kraut, J. Crystal Structures of d,l-Homocysteine Thiolactone Hydrochloride: Two Polymorphic Forms and a Hybrid. Acta Crystallogr. 1965, 19, 992-1002.

(18) Dugarte, N. Y.; Erben, M. F.; Romano, R. M.; Boese, R.; Ge, M.F.; Li, Y.; Della Védova, C. O. Matrix Photochemistry, Photoelectron Spectroscopy, Solid-Phase Structure, and Ring Strain Energy of $\beta$ Propiothiolactone. J. Phys. Chem. A 2009, 113, 3662-3672.

(19) Dugarte, N. Y.; Erben, M. F.; Romano, R. M.; Ge, M.-F.; Li, Y.; Della Védova, C. O. Matrix Photochemistry at Low Temperatures and Spectroscopic Properties of $\gamma$-Butyrothiolactone. J. Phys. Chem. A 2010, 114, 9462-9470.

(20) Dugarte, N. Y.; Erben, M. F.; Boese, R.; Ge, M.-F.; Yao, L.; Della Védova, C. O. Molecular and Electronic Structure of $\delta$-Valerothiolactone. J. Phys. Chem. A 2011, 114, 12540-12547.

(21) Huber, C.; Wächtershäuser, G. Peptides by Activation of Amino Acids with $\mathrm{CO}$ on $(\mathrm{Ni}, \mathrm{Fe}) \mathrm{S}$ Surfaces: Implications for the Origin of Life. Science 1998, 281, 670-672.

(22) Huber, C.; Wächtershäuser, G. Activated Acetic Acid by Carbon Fixation on (Fe,Ni)S Under Primordial Conditions. Science 1997, 276, 245-247.
(23) Bracher, P.; Snyder, P.; Bohall, B.; Whitesides, G. The Relative Rates of Thiol-Thioester Exchange and Hydrolysis for Alkyl and Aryl Thioalkanoates in Water. Orig. Life Evol. Biosph. 2011, 41, 399-412.

(24) Rodríguez Pirani, L. S.; Geronés, M.; Della Védova, C. O.; Romano, R. M.; Fantoni, A.; Cavasso-Filho, R.; Ma, C.; Ge, M.; Erben, M. F. Electronic Properties and Dissociative Photoionization of Thiocyanates. Part II. Valence and Shallow-Core (Sulfur and Chlorine $2 \mathrm{p}$ ) Regions of Chloromethyl Thiocyanate, $\mathrm{CH}_{2} \mathrm{ClSCN}$. J. Phys. Chem. A 2012, 116, 231-241.

(25) Wang, W.; Yao, L.; Zeng, X.; Ge, M.; Sun, Z.; Wang, D.; Ding, Y. Evidence of the Formation and Conversion of Unstable Thionyl Isocyanate: Gas-Phase Spectroscopic Studies. J. Chem. Phys. 2006, 125, $234303-234306$

(26) Wang, W.; Ge, M.; Yao, L.; Zeng, X.; Sun, Z.; Wang, D. GasPhase Spectroscopy of the Unstable Sulfur Diisocyanate Molecule $\mathrm{S}(\mathrm{NCO})_{2}$. ChemPhysChem 2006, 7, 1382-1387.

(27) CrysAlisPro, Oxford Diffraction Ltd., Version 1.171.33.48 (release 15-09-2009 CrysAlis171.NET).

(28) Sheldrick, G. Phase Annealing in SHELX-90: Direct Methods for Larger Structures. Acta Crystallogr. 1990, A46, 467-473.

(29) Sheldrick, G. A short history of SHELX. Acta Crystallogr. 2008, A64, 112-122.

(30) Frisch, M. J.; Trucks, G. W.; Schlegel, H. B.; Scuseria, G. E.; Robb, M. A.; Cheeseman, J. R.; Montgomery Jr., J. A.; Vreven, T.; Kudin, K. N.; Burant, J. C.; et al. Gaussian 03, Revision B.04.; Gaussian, Inc.: Pittsburgh, PA, 2003.

(31) Cederbaum, L. S.; Domcke, W. Theoretical Aspects of Ionization Potentials and Photoelectron Spectroscopy: a Green's Function Approach. Adv. Chem. Phys. 1977, 36, 205-344.

(32) Cederbaum, L. S.; Schirmer, J.; Domcke, W.; von Niessen, W. Complete Breakdown of the Quasiparticle Picture for Inner Valence Electrons. J. Phys. B 1977, 10, L549-L553.

(33) Zhao, M.; Gimarc, B. M. Strain Energies in Cyclic Oxygen On, n = 3-8. J. Phys. Chem. 1993, 97, 4023-4030.

(34) Cogley, C. D. Microwave Studies of $\varepsilon$-Caprolactone. J. Phys. Chem. 1987, 91, 4235-4237.

(35) Emelyanenko, V.; Verevkin, S.; Stepurko, E.; Roganov, G.; Georgieva, M. Thermodynamical Properties of $\varepsilon$-Caprolactone. Russ. J. Phys. Chem. A 2010, 84, 356-363.

(36) Brandenburg, K. DIAMOND-3.2h, Crystal Impact GbR, Bonn, Germany, 1999-2011.

(37) Vujasinovic, I.; Veljkovic, J.; Mlinaric-Majerski, K.; Molcanov, K.; Kojic-Prodic, B. Solid-State Tubular Assemblies of Thiolactones: Synthesis and Structural Characterization. Tetrahedron 2006, 62, 2868-2876.

(38) Vujasinovic, I.; Veljkovic, J.; Molcanov, K.; Kojic-Prodic, B.; Mlinaric-Majerski, K. Thiamacrocyclic Lactones: New Ag(I)-Ionophores. J. Org. Chem. 2008, 73, 9221-9227.

(39) Setzer, W. Conformational Analysis of Thioether Musks Using Density Functional Theory. Int. J. Mol. Sci 2009, 10, 3488-3501.

(40) Ang, H. G.; Klapdor, M. F.; Kwik, W. L.; Lee, Y. W.; Mack, H. G.; Mootz, D.; Poll, W.; Oberhammer, H. O-Nitrosobis(trifluoromethyl)hydroxylamine: Unexpected Conformational Properties and an Unusually Long $\left(\mathrm{CF}_{3}\right)_{2} \mathrm{NO}-\mathrm{NO}$ Bond. A Combined Study of the Gaseous and Solid States. J. Am. Chem. Soc. 1993, 115, 69296933.

(41) Erben, M. F.; Della Védova, C. O.; Willner, H.; Trautner, F.; Oberhammer, H.; Boese, R. Fluoroformyl Trifluoroacetyl Disulfide, $\mathrm{FC}(\mathrm{O}) \mathrm{SSC}(\mathrm{O}) \mathrm{CF}_{3}$ : Synthesis, Structure in Solid and Gaseous States, and Conformational Properties. Inorg. Chem. 2005, 44, 7070-7077.

(42) Erben, M. F.; Boese, R.; Della Védova, C. O.; Oberhammer, H.; Willner, $\mathrm{H}$. Toward an Intimate Understanding of the Structural Properties and Conformational Preference of Oxoesters and Thioesters: Gas and Crystal Structure and Conformational Analysis of Dimethyl Monothiocarbonate, $\mathrm{CH}_{3} \mathrm{OC}(\mathrm{O}) \mathrm{SCH}_{3}$. J. Org. Chem. 2006, 71, 616-622.

(43) Della Védova, C. O.; Romano, R. M.; Oberhammer, H. Gas Electron Diffraction Analysis on S-Methyl Thioacetate, $\mathrm{CH}_{3} \mathrm{C}(\mathrm{O})$ $\mathrm{SCH}_{3}$. J. Org. Chem. 2004, 69, 5395-5398. 
(44) Kenneth, B. W. The Concept of Strain in Organic Chemistry. Angew. Chem. Int. Ed. 1986, 25, 312-322.

(45) Ringer, A. L.; Magers, D. H. Conventional Strain Energy in Dimethyl-Substituted Cyclobutane and the gem-Dimethyl Effect. J. Org. Chem. 2007, 72, 2533-2537.

(46) Borst, M. L. G.; Ehlers, A. W.; Lammertsma, K. G3(MP2) Ring Strain in Bicyclic Phosphorus Heterocycles and Their Hydrocarbon Analogues. J. Org. Chem. 2005, 70, 8110-8116.

(47) Bach, R. D.; Dmitrenko, O. The Effect of Carbonyl Substitution on the Strain Energy of Small Ring Compounds and Their SixMember Ring Reference Compounds. J. Am. Chem. Soc. 2006, 128, $4598-4611$.

(48) Saiyasombat, W.; Molloy, R.; Nicholson, T. M.; Johnson, A. F.; Ward, I. M.; Poshyachinda, S. Ring Strain and Polymerizability of Cyclic Esters. Polymer 1998, 39, 5581-5585.

(49) Ulic, S. E.; Coyanis, E. M.; Romano, R. M.; Della Védova, C. O. S-Ethyl Thiochloroformate, $\mathrm{ClC}(\mathrm{O}) \mathrm{SCH} 2 \mathrm{CH} 3$ : Unusual Conformational Properties? Spectrochim. Acta 1998, A54, 695-705.

(50) Kuźyants, G. M. Vibrational Spectra of $\beta$-Thiopropiolactone. J. Struct. Chem. 1975, 696-699.

(51) Nagata, S.; Yamabe, T.; Fukui, K. Electronic Spectra of Thioacetic Acid and Its Ethyl Ester. J. Phys. Chem. 1975, 79, 23352340.

(52) Erben, M. F.; Della Védova, C. O. Dramatic Changes in Geometry After Ionization: Experimental and Theoretical Studies on the Electronic Properties of Fluorocarbonyl (Mono-, Di-, and Tri-) Sulfur Compounds. Inorg. Chem. 2002, 41, 3740-3748.

(53) Fausto, R. Bonding in Carbonyl and Thiocarbonyl Compounds: an $\mathrm{Ab}$ initio Charge Density Study of $\mathrm{H}_{2} \mathrm{C}=\mathrm{X}$ and $\mathrm{HC}(=\mathrm{X}) \mathrm{YH}(\mathrm{X}, \mathrm{Y}$ = O or S). J. Mol. Struct.: THEOCHEM 1994, 315, 123-136.

(54) Erben, M. F.; Della Védova, C. O.; Romano, R. M.; Boese, R.; Oberhammer, H.; Willner, H.; Sala, O. Anomeric and Mesomeric Effects in Methoxycarbonylsulfenyl Chloride, $\mathrm{CH}_{3} \mathrm{OC}(\mathrm{O}) \mathrm{SCl}$ : An Experimental and Theoretical Study. Inorg. Chem. 2002, 41, 10641071.

(55) Chin, W. S.; Xu, Z. P.; Mok, C. Y.; Huang, H. H.; Mutoh, H.; Masuda, S. He I and He II Photoelectron Spectra of Thiophenones. J. Electron Spectrosc. Relat. Phenom. 1998, 88-91, 97-101.

(56) Isaksson, R; Liljefors, T. Ab Initio Calculations and Photoelectron Spectra of Cyclic Oxamides. J. Chem. Soc., Perkin Trans. 2 1980, $1815-1820$. 